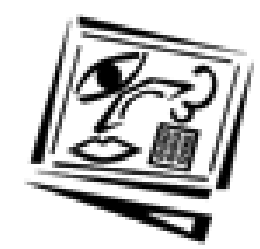

\author{
Australian Journal of \\ Educational Technology
}

2002, 18(3), 341-358

\title{
Tertiary computing course selection: The impact of mathematics anxiety on female decision making
}

\author{
Catherine Lang \\ Swinburne University of Technology
}

\begin{abstract}
Is mathematics anxiety contributing to the declining numbers of females enrolling in tertiary computing courses? Initial observation of enrolments in tertiary computing courses at an Australian university suggests a direct correlation between the number of females in a course and the prerequisite level of mathematics required at entry. A study involving over 550 female students in Australia and Singapore was undertaken to determine student perceptions of the importance of mathematics to computing and information technology degrees. All of the students were either studying a computing subject at secondary school or university and some were already enrolled in a computing degree. Results indicate that students studying computing at tertiary level in both countries believe that computing courses require good mathematical ability, while secondary school students express high levels of uncertainty when asked the same question. The majority of students surveyed believe that females and males are equal in mathematical ability, while thirty percent of the cohort from Singapore believes that males are more able than females in mathematical ability. This paper uses these responses, combined with observation and statistical data, to posit that females perceive a strong link between mathematical ability and success in computing courses. Consequently mathematics anxiety in females could be a contributing factor to their under-representation in tertiary computing courses. Computing and mathematics educators need to combine their efforts to encourage females into computing courses and dispel this anxiety.
\end{abstract}

\section{Introduction}

The number of males enrolling in computing degrees at an Australian university in 1996 outnumbered females by more than 2 to 1 . It was observed that this ratio did not apply to the international student enrolments in the same courses. Often the number of international female students enrolling marginally outnumbered males. This gender imbalance was occurring at a time when the total proportion of female students at the same university had been steadily increasing to more than half of the 
student body (52.3\% in 1995, 55\% in 2000). The trend of declining numbers of females enrolling in computing degrees had been observed in several other universities in Australia and also in other western countries (Klawe \& Leveson, 1995; DETYA, 2001). The gender imbalance in this field has been a major concern to researchers and key players in the computing field over the last 30 years (Siann \& Callahan, 2001) partly because young women do not appear to be giving due consideration to the career path.

\footnotetext{
If access to and control of technologies bestows power, women disenfranchise themselves by ignoring or rejecting technology (Spender, 1995, p.35).
}

A closer investigation of the Monash enrolment statistics showed an apparent correlation between the level of difficulty of the mathematics prerequisite required for a computing course, and the percentage of females enrolled in that course. This study aims to evaluate how much the perception of computing being a technical discipline based on the prerequisite mathematical entry requirement influenced female students' course choices.

\section{Background}

The implication that a strong mathematical base is needed to be successful in computing is reaffirmed by the majority of computing courses at Monash University requiring mathematics as a prerequisite subject. There were seven courses classed as computing courses in the Faculty of Information Technology at Monash University, Australia in 1996. Table 1 shows the gender breakdown of first year on campus enrolments and the mathematics prerequisite of each of the courses. These numbers include domestic and international students.

At the time of this study there were three mathematics courses available to final year (Year 12) students in the Victorian Certificate of Education (VCE). Firstly, Further Mathematics, considered a generalist course suitable for students contemplating employment or tertiary study without a strong mathematical component. This subject covered the areas of data sets, statistical concepts, arithmetic, algebra and some geometry used to solve routine problems. Secondly Mathematical Methods, the more advanced application intended to provide a good foundation for further study in science, economics or medicine and the norm for further study in computer science. Lastly Specialist Mathematics, aimed at serious mathematics students with strong ability in the area wishing to undertake further study in mathematics related disciplines. It was and still is the most complex mathematics subject available at secondary school. 
Table 1: Monash IT course enrolments

\begin{tabular}{|c|c|c|}
\hline Name of course & $\begin{array}{c}\% \text { First Year on } \\
\text { campus females } \\
\text { in course }\end{array}$ & Mathematics prerequisite \\
\hline $\begin{array}{l}\text { Bachelor of Information } \\
\text { Management }\end{array}$ & $48 \%$ & No mathematical prerequisite \\
\hline Bachelor of Business Systems & $36 \%$ & Year 11 mathematics \\
\hline $\begin{array}{l}\text { Bachelor of Computing } \\
\text { (Peninsula Campus) }\end{array}$ & $36 \%$ & Year 11 mathematics \\
\hline $\begin{array}{l}\text { Bachelor of Computing } \\
\text { (Caulfield Campus) }\end{array}$ & $30 \%$ & Year 11 mathematics \\
\hline $\begin{array}{l}\text { Bachelor of Computing - } \\
\text { Computer Science }\end{array}$ & $16 \%$ & $\begin{array}{l}\text { Year } 12 \text { Mathematical Methods } \\
\text { (Specialist Mathematics and } \\
\text { physics recommended) }\end{array}$ \\
\hline $\begin{array}{l}\text { Bachelor of Computing } \\
\text { (Gippsland Campus) }\end{array}$ & $10 \%$ & Year 12 mathematics (any) \\
\hline Bachelor of Digital Systems & $7 \%$ & $\begin{array}{l}\text { Year } 12 \text { Mathematical Methods } \\
\text { (Specialist Mathematics and } \\
\text { physics recommended) }\end{array}$ \\
\hline
\end{tabular}

Source: Monash University, Budget and Statistical Services

The Bachelor of Digital Systems and the Bachelor of Computer Science both required Mathematical Methods as a prerequisite, with Specialist Mathematics and Physics recommended. Both courses had a very small percentage of female enrolments, $7 \%$ and $16 \%$ respectively (Table 1 ). At the other end of the scale, the Bachelor of Information Management has no mathematical requirement, and had the highest percentage of female enrolments (48\%). As can be seen in Table 1, as the prerequisite level of mathematics increases, the number of females in each course decreased. Further emphasising this pattern is The Bachelor of Computing at the Gippsland Campus that required Year 12 mathematics as a prerequisite and had 10\% female enrolment, while the same degree at Caulfield and Peninsula Campuses required year 11 mathematics and had 30\% and 36\% female enrolments, respectively. The Faculty had an overall female enrolment of $27 \%$.

On an Australia wide scale, Department of Employment Training and Youth Affairs (DETYA) statistics presented in Table 2 indicate that computing courses that require the lowest level mathematics prerequisite attracted the largest number of female enrolments, and that the trend of females turning their back on this career path is increasing.

The classifications in Table 2 are those used when gathering data from all Australian universities. The pattern observed in the Monash enrolment is mirrored in the Australia wide statistics. The "harder" computing 
classified as computer science, which requires a higher mathematics for entrance, had the least number of full time female enrolments (decreased by 3\% over 3 years). The more generalist "soft" courses (Information Systems and the last classification that includes Business Data Processing) had the highest percentage of female enrolments (also a decrease of $7 \%$ female enrolment over last 3 years). The national percentage of female international students in the computer science and information systems field of study in all Australian institutions was 44\% in 1995, and 34\% in 1999.

Table 2: Australia wide statistics

\begin{tabular}{|l|c|c|}
\hline \multirow{2}{*}{\multicolumn{1}{|c|}{ DETYA classification }} & \multicolumn{2}{c|}{$\%$ full time females in courses } \\
\cline { 2 - 3 } & 1996 & 1999 \\
\hline $\begin{array}{l}\text { 9.02.01 Computer Science, Information } \\
\text { Systems - General (not Business Data } \\
\text { Processing) }\end{array}$ & $31.4 \%$ & $23 \%$ \\
\hline 9.02.02 Computer Science & $22 \%$ & $19 \%$ \\
\hline 9.02.03 Information Systems & $44 \%$ & $33 \%$ \\
\hline $\begin{array}{l}\text { 9.02.99 Computer Science, Information } \\
\text { Systems - other }\end{array}$ & $44 \%$ & $34 \%$ \\
\hline
\end{tabular}

Source: DETYA, Data Services and Resources Branch (2001)

\section{Gender inequity in computing career paths}

Much has been written regarding the apparent gender inequity in computing career paths. Turkle (1995) defined the cultural construction of computing as the identity of being a woman with all that a computer is not, and computers with all that a woman is not. She links this with the emergence of scientific thought where "hard" thought was linked to the "pure" forms of scientific thinking - pure mathematics, pure science, and "soft" thinking for the non-hierarchical style that is more flexible and negotiative. The styles are neither unique to males or females, but girls are trained in the skills of a "soft" approach to thinking.

We train girls in the component skills of a soft approach - negotiation, compromise, give and take - as psychological virtues, while dominant models of desirable male behaviour stress decisiveness and the imposition of wills (Turkle, 1995, p.56).

Beall and Sternberg (1993) stated that gender is a socially constructed category that differs across cultures and quoted examples of these differences in several cultures. The gender schema of western society is portrayed as males being dominant and liking mathematics and science, while females are the passive members, not liking mathematics and science. When the gender schema was applied in tests and observers were asked to assign gender to behaviour, people interpreted any dominant behaviour as male (Beall \& Sternberg, 1993, p.114). 
Many of these researchers drew on the understanding that females have different learning styles from males and different preferred modes of instruction. Belenky, Clinchy, Goldberger and Tarule (1986) conducted a 5-year study in America interviewing 135 women and analysing the perspectives from which women view reality and draw conclusions about truth, knowledge and authority. The resulting descriptive phenomenon is referred to as five different ways of knowing. Belenky et al discussed the cultural conditioning of females and how that influenced their learning. They claim that many women do not move past the subjective state of knowing, and that those who do move on to believing knowledge as a construction, a state that most males attain, are inhibited by social expectations of female behaviour. Koertge (1995) disagreed with the claims made by Belenky et al, that the standard norms and methods of scientific inquiry are sexist because they are incompatible with women's ways of knowing, and argued that society must simply place more value on material thinking. She disputed the claims made by many feminist groups that logic is a tool of domination (Koertge, 1995, p.43).

Other research in the field draws attention to the increasing emergence of sex differences in the use of computer technology in education (Hawkins, 1985). As early as 1985, when PC labs were becoming common in most secondary schools, it was observed that because computers were assimilated to the category of science, mathematics and technology, the discipline of computer science was acquiring a gender differentiated interest associated with these fields. A survey of over 17,000 American students (Fetler, 1985) found that boys outscored girls in all areas of computer literacy. In this study, sixth and twelfth grade students were surveyed during the 1982-1983 school year and the analysis was organised under the headings of performance, attitude and experience. Boys outscored girls in every major area in performance, girls generally had a less positive attitude towards computers, and there was an overall pattern of lesser experience with computers both at school and at home for girls. It is acknowledged that this is old data for the computing discipline, but it shows a trend reaffirmed by a more recent Australian study (Australian Bureau of Statistics, 1999) that compared children's advanced computer skills by gender. In this study boys outscored girls in twelve out of the thirteen areas.

Koch (1994) referred to a "Women in Industry" program that involved female computing professionals visiting schools and talking to students in the 11-15 year old age groups. Some results from this program included the observation that the number of females in the computing club at one school increased from 5\% to 53\%, and the number of females enrolled in programming increased to $31 \%$ from zero in another school. Koch emphasised the importance of demonstrating that females can be 
competent scientists, mathematicians, engineers and computer scientists, to help overcome social stereotyping to both male and female students (Koch, 1994, p.7)

The general belief in the literature is that society encourages males to be inquisitive and technical minded to a greater extent than females. This influences the choices females make from a very early age and impacts on their desire to follow career paths that may be perceived to be of a technical nature, and since computing evolved from the mathematics and science area, it is seen to be technical. The aim of this study was to test the hypothesis that females perceive a strong link between mathematical ability and success in computing courses.

\section{Data collection method}

Data was collected from a number of sources. Over 550 surveys were collected from secondary and tertiary students in Singapore and Australia. These surveys were supported by 25 follow up interviews with tertiary students in Australia as well as with females working in the information technology field. The tool used was a questionnaire constructed with three distinct sections, (i) background information, (ii) statements requiring Likert scale responses that were used to elicit opinions and the strength of the opinion, and (iii) open ended questions to elicit reasons and further details. Data was gathered from females only, because it was the opinions and perceptions of this group that were critical to the research and therefore needed to be ascertained.

All first year female Monash computing and information technology students were surveyed either at the end of a core lecture or during a practical laboratory session. There were varying response rates, which could not be avoided due to the wholly voluntary nature of the survey. The total number of students surveyed was 168 . The questionnaire was administered to 256 VCE students from regional secondary colleges, as well as students from two schools considered exemplary in their use of computers. All students were studying VCE Information Technology or had studied it in previous years. The questionnaire was administered to 133 students from three levels of educational institutions in Singapore, including two junior colleges (equivalent to senior secondary schools in Australia) and two polytechnics. The questionnaire was also administered to first year computing students at the National University of Singapore and to students from a private computing school that acts as an agent for Monash University and assists in the delivery of distance learning courses.

A small number of the students who had completed the questionnaire from each Monash campus and each of the courses agreed to meet for a 
group discussion session. These focus groups were used to augment the data from the questionnaire. A total of 19 current first year undergraduates took part in these focus group sessions. The Australian Computing Society (ACS) provided a list of females who were currently working in the information technology field. Four professionals were interviewed to determine if the perceived mathematical ability required in computing had changed over time. Their positions ranged from a self employed businesswoman to a public service professional. Very similar questions to those used in the questionnaire were used as a basis for these interviews.

This method of data collection provided both quantifiable statistical data and qualitative data. The surveys were distributed in early 1996 and the interviews were conducted later in the year.

\section{Description of sample data}

In summary the average female Monash undergraduate in the sample is most likely to be 19 years of age or younger $(80 \%)$, with almost half the sample being 18 years old, she is attending a city campus of Monash University, and there is a slightly greater chance that she attended a nongovernment secondary school (48\%) than a government school $(40 \%)$. The average Singaporean student in the sample is slightly older than the Monash student (47\% were 20 years or older) and she is attending a polytechnic $(49 \%)$. The average secondary school student in the sample attends a government school $(62 \%)$, is 17 year of age or less $(90 \%)$, and has completed or is currently studying Year 11 Information Technology $(80 \%)$.

\section{Analysis and discussion}

Responses from the questions listed were deemed pertinent to the hypothesis that females perceive a strong link between mathematical ability and success in computing courses:

- What are the 3 most important skills required for success in the computing field?

- Good mathematical ability is needed for success in computing degree courses (eliciting a Likert scale response from strongly agree to strongly disagree).

- Men are better at mathematics than women (also eliciting a Likert scale response).

- What mathematics subjects have you completed? (write course name and unit number (eg. Further Mathematics 3 \& 4) 
The responses to the question "What is the most important skill required for success in the computing field?" were categorised into the areas detailed in Table 3 after analysing a sample of responses.

Table 3: What is most important skill needed?

\begin{tabular}{|l|c|c|c|}
\hline & Monash $\%$ & Singapore $\%$ & Secondary $\%$ \\
\hline Prior computing knowledge & 29.8 & 24.3 & 50.0 \\
\hline Logical thinking (mathematics ability) & 23.8 & 31.3 & 8.4 \\
\hline Communication skills & 12.5 & 22.6 & 0.9 \\
\hline Patience & 10.7 & 6.1 & 7.9 \\
\hline Programming & 8.3 & & 0.9 \\
\hline Interest & 2.4 & 7.8 & 4.7 \\
\hline Cope with constant change & 1.8 & 3.5 & 3.3 \\
\hline Keyboarding & & & 21.5 \\
\hline Don't know & & & 2.3 \\
\hline Creativity & & 4.3 & \\
\hline No data & 10.7 & & \\
\hline
\end{tabular}

Monash students most frequently mentioned "Prior computing knowledge" as the most important skill needed in computing courses $(29.8 \%)$. The logical thinking responses were interpreted as referring to mathematical ability, and while this was not the first skill listed by the majority of Monash respondents, it was listed by $23.8 \%$ of the students as the second most frequently mentioned skill. It was the most important skill listed by the Singaporean students.

When the responses from the Monash students were cross tabulated with the courses the students were enrolled in, the biggest group who rated logical thinking as the most important skill were those students in noncomputing degrees. These students were studying one computing subject as an elective, or as a minor stream in their degree in another discipline.

Some comments made in follow up interviews to the same question show that the ability to think logically is considered very important.

I think that it is just that you need to be able to understand the concepts involved and apply them - S1

You need to be logical. S2 non-computing students

For software development, the capability for logical clear thinking, being challenged by problems being excited by technology. P5 Self employed professional 
I think you have to be able to think very logically, I think that competition is really going to arise, and I think that you need to be pretty assertive. In system analysis you need to be able to take things apart and look at them separately. S3 Bachelor of Computing

One third of the Singaporean students surveyed (31.3\%) listed logical thinking as the most important skill required, prior knowledge was the next largest response (24.3\%), followed by communication skills $(22.6 \%)$. Some typical responses to this question were:

Logical thinking and understanding the limitations of computers.

Singapore 9

Technology aspect (knowledge of both the hardwares (sic) and software), good communication skills with others and good human management. Singapore 16

Analytical mind, good mathematical/programming knowledge and capability to produce what is requested. Singapore 21

Strong communications skill. Good programming background/skill and methodlogy (sic). Good time and stress management skill. Singapore 20

The results from secondary school students to the same question asking what is the most important skill needed for computing did not show that mathematics was a priority. The most common response was some sort of prior computing knowledge or experience earlier in their secondary education. Only $8.4 \%$ listed logical or analytical skills, which relate to mathematical ability, as being important.

Be logical, determine what problem you have to solve. Secondary school 38

Typeing (sic), basic computer knowledge, logical thinking Secondary school 39

Mathematical mind, logical thinking, understanding technology Secondary school 52

Typing, good mathematics skills and you need a wide knowledge of technology. Secondary school 88

These results show that the secondary school students do not have as strong a perception as the Monash students of the link between mathematical skills and computing.

Two statements in section (ii) of the survey were used to ascertain perceptions about mathematics and computing. The responses to the statement, "Good mathematical ability is needed for success in computing degree courses" are shown in Figure 1 with 54.1\% of the Monash students 
agreeing or strongly agreeing with this statement, and $20.8 \%$ disagreeing. The Singaporean students are even stronger in their affirmation with $67.7 \%$ agreeing or strongly agreeing. The majority of the secondary school students either disagree or are uncertain, and under one third agree with the statement.

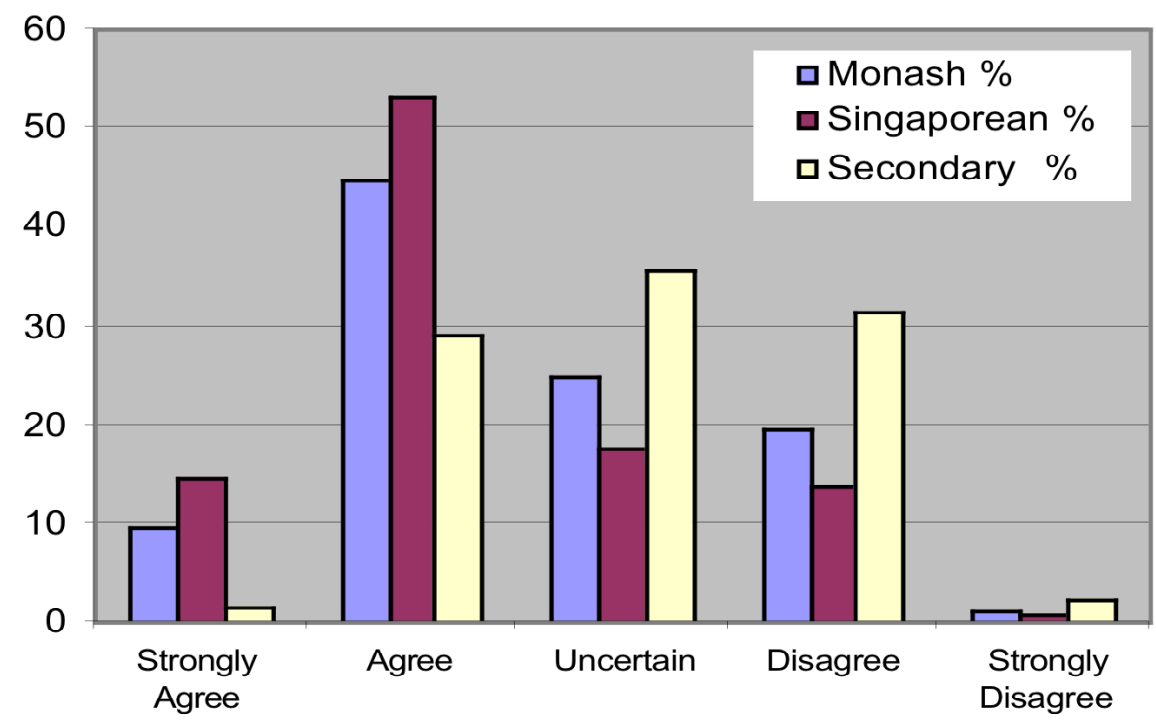

Figure 1: Good mathematics ability is needed

In follow up interviews Monash students' comments show that views on the need for mathematics vary between courses.

I don't like mathematics so I would probably emphasise that there is not a lot of mathematics.(but I did do Methods in Year 12.) - S3 Bachelor of

Computing

Before coming they should have mathematics. We do need it. Most of the people did not do it in high school. You do need it. At least Further

Mathematics, need a Year 12 Mathematics. - S2 Bachelor of Business Systems

The deliberately provocative statement "Men are better at mathematics than women", resulted in $71.4 \%$ of the Monash respondents disagreeing or strongly disagreeing with the statement. Interestingly $32.4 \%$ of the Singaporean students believed that men are better at mathematics than women. Considering the age of the sample and the fact that a large percentage of the sample consisted of well-educated females, the high percentage of assent as well as the uncertainty is surprising $(51.6 \%)$. The 
secondary school students are the firmest in opposition to the statement, with $86.7 \%$ of the sample either disagreeing or strongly disagreeing.

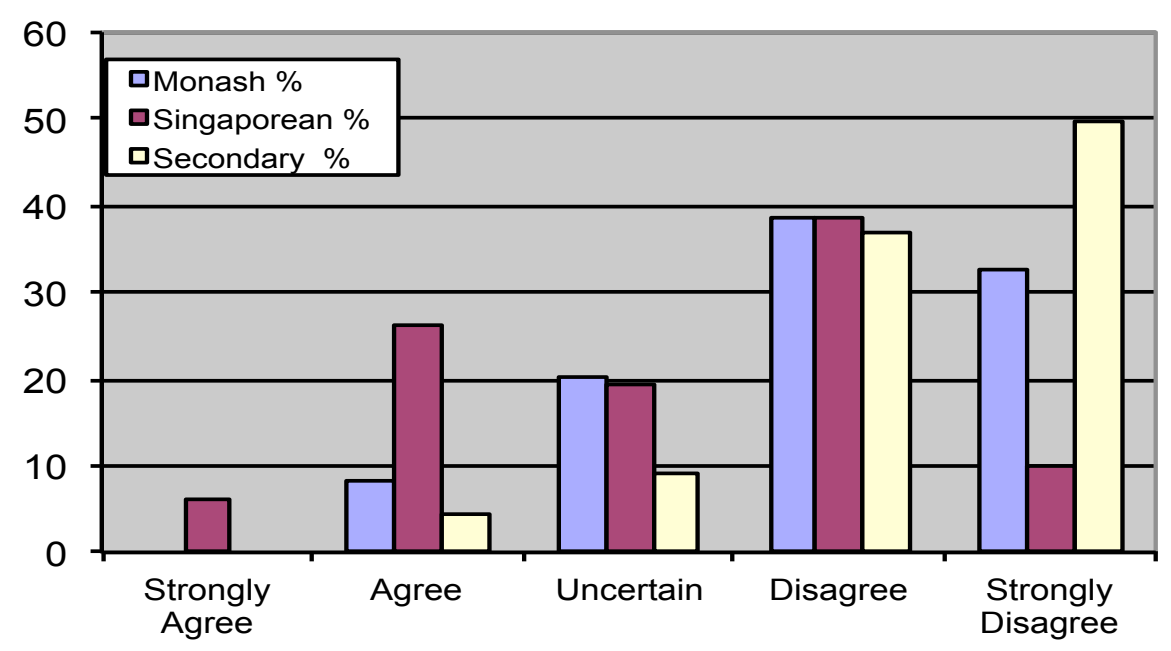

Figure 2: Men are better at mathematics than women

Some of the literature in the field disputes the belief that men are better at mathematics than women because of a better ability. A study completed in 1989 stated that they were only better because they had completed more mathematics in their schooling (Clarke \& Teague, 1994 p. 259). This was also noticed by one of the students interviewed whose comments support the belief that it is a lack of exposure to certain forms of mathematics, rather than a lack of ability, that hinders the progress of females in computing.

Then you come and have to do data logic and some programming, like I came into this course and I didn't know what the hell programming was, like at all, and even data logic. And like I'm talking to my male friends, and I said, like, where did you learn this stuff? How come you already know this? And they say, oh we did it in Year 10, and a bit in Specialist

Mathematics - S2 Bachelor of Computer Science

While Specialist Mathematics is available to males and females, it does not have a good gender balance with only $35 \%$ of the total enrolment being female in 1996 and 36\% in 2000 (Board of Studies, 2001).

I was from a co-ed school, yeah, I was actually, we had a small Physics class and I was the only girl out of 13 people, and in Specialist Mathematics as well, I was the only girl out of 26 . -S3 non-computing student 
The responses to the question "What mathematics subjects have you completed?" were classified into one year, two years, or more than two years. $61.9 \%$ of the respondents had completed two years of senior secondary mathematics or more, as indicated in Figure 3. Very few of the students surveyed had not completed any senior secondary mathematics.

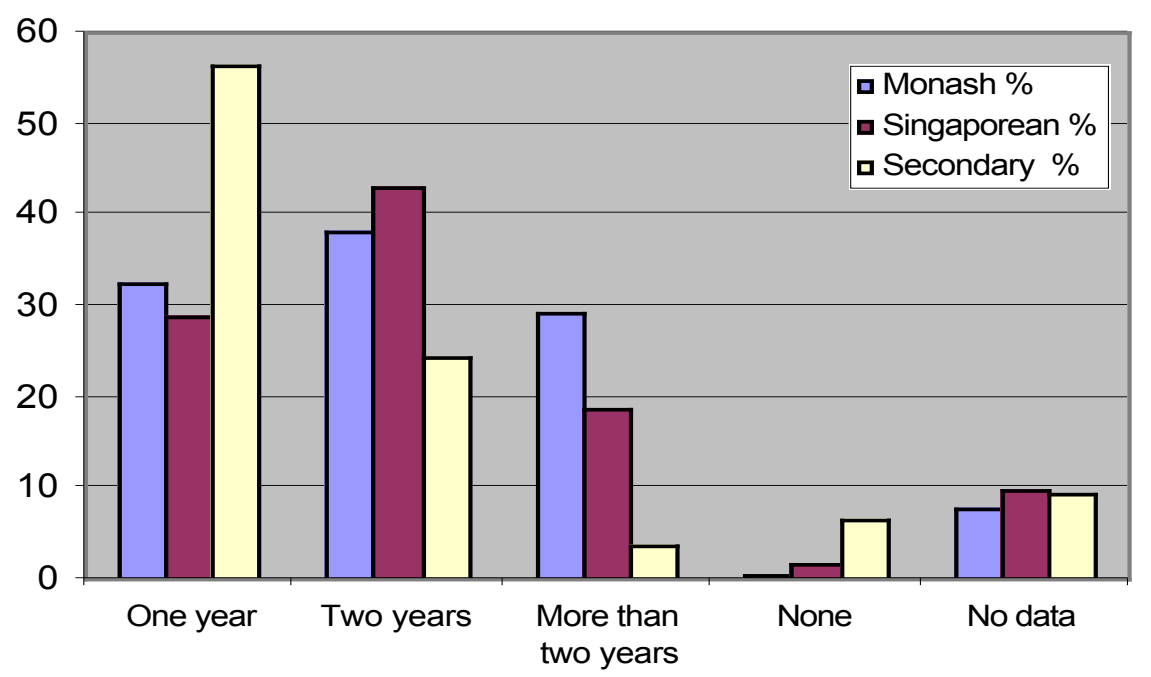

Figure 3: Years of senior secondary school mathematics completed

Mathematics is considered an important subject and a prerequisite for many university courses and generally most students are counseled to keep it in their secondary school course for as long as their ability allows. The results shown in Figure 3 indicate that very few students do not complete any final year mathematics courses.

\section{Statistical significance}

To establish the statistical significance of the responses from the three groups, one way analysis of variance (ANOVA) and Post Hoc analysis (Scheffe) tests were conducted. The ANOVA test was used to determine if differences in responses between the three cohorts were likely to have occurred by chance or not, and the Post Hoc (Sheffe) test to determine the nature of any statistical difference.

The critical focus of the ANOVA results are that the secondary school students surveyed are the least diverse in their opinions, when compared with the other two cohorts. Table 4 shows that the differences between 
each of the three samples on whether good mathematical ability is needed for success in computing degree courses is unlikely to have happened by chance $(\mathrm{F}(2,551)=29.333, \mathrm{p}<.001)$. The secondary school students have the highest mean (3.04) and the lowest standard deviation (.87), indicating that this group in general has a greater disagreement with the statement than the other two groups. The Singaporean students agree most with the statement (lowest mean 2.33) and the Monash group has the greatest spread in their responses (SD .95).

Table 4: ANOVA results: Opinions on mathematical ability needed for computing, and differing mathematical ability between males and females.

\begin{tabular}{|l|c|c|c|c|c|c|c|c|}
\hline & \multicolumn{2}{|c|}{ Monash } & \multicolumn{2}{|c|}{$\begin{array}{l}\text { Secondary } \\
\text { School }\end{array}$} & \multicolumn{2}{l|}{ Singaporean } & \multicolumn{2}{c|}{ ANOVA } \\
\cline { 2 - 9 } & Mean & SD & Mean & SD & Mean & SD & $\begin{array}{c}\text { F } \\
(2,551)\end{array}$ & P \\
\hline $\begin{array}{l}\text { Good mathematical ability } \\
\text { is needed for success in } \\
\text { computing degree courses }\end{array}$ & 2.58 & .95 & 3.04 & .87 & 2.33 & .92 & 29.553 & .001 \\
\hline $\begin{array}{l}\text { Men are better at } \\
\text { mathematics than women }\end{array}$ & 3.96 & .93 & 4.32 & .81 & 3.20 & 1.12 & 62.747 & .001 \\
\hline
\end{tabular}

The opinion that men are better at mathematics than women also shows significant differences $(\mathrm{F}(2,551)=62.747, \mathrm{p}<.001)$. The responses to this statement once more show the secondary school students have the strongest disagreement (mean 4.32) with the statement and that their responses are the least spread (SD .81). The Singaporean cohort has the least strength of disagreement (mean 3.20), and the most spread in the responses (SD 1.12).

The responses to these statements could also be interpreted to be merely a reflection of the fact that males actually do study more mathematics than females in both Australia and Singapore, and the egalitarianism of the youngest cohort could be a support for their stronger disagreement with the statements.

The Post Hoc (Scheffe) analysis in Table 5 shows significant differences in the means of the Monash and secondary school groups, but not between the Monash and Singapore groups, in the responses to the statement that good mathematical ability is needed for success in computing degree courses. Both the Monash and Singaporean cohorts have studied more computing, and both groups agree with the statements indicating that their increased knowledge of the area should be taken into account. The secondary school students have a greater disagreement with the statement than either of the other two groups. They are the youngest 
cohort and also the group with the least computing experience, which could account for the difference in their responses.

Table 5: Post Hoc (Scheffe) test: Opinions on mathematical ability needed for computing, and differing mathematical ability between males and females.

\begin{tabular}{|l|c|c|c|}
\hline \multicolumn{1}{|c|}{ Dependent Variable } & Groups (G1) & Groups (G2) & $\begin{array}{c}\text { Mean Difference } \\
\text { (G1-G2) }\end{array}$ \\
\hline \multirow{4}{*}{$\begin{array}{l}\text { Good mathematical ability } \\
\text { is needed for success in } \\
\text { computing degree course }\end{array}$} & Monash & $\begin{array}{c}\text { Sec.School } \\
\text { Singapore }\end{array}$ & $\begin{array}{c}-.46^{*} \\
.25\end{array}$ \\
\cline { 2 - 4 } & Sec.School & Monash & $.46^{*}$ \\
\cline { 2 - 4 } & Singapore & $.71^{*}$ \\
\hline \multirow{2}{*}{$\begin{array}{l}\text { Men are better at } \\
\text { mathematics than women }\end{array}$} & Monash & Monash & -.25 \\
& & Sec. School & $-.71^{*}$ \\
\cline { 2 - 4 } & Sec.School & Singapore & $-.36^{*}$ \\
\cline { 2 - 4 } & & Monash & $.76^{*}$ \\
\cline { 2 - 4 } & Singapore & Singapore & $1.16^{*}$ \\
\hline & & Monash & $-.76^{*}$ \\
& & & $-1.12^{*}$ \\
\hline
\end{tabular}

When expressing an opinion on whether men are better at mathematics than women, the Post Hoc (Scheffe) analysis shows significant differences in the means of all three groups. The secondary school students have a greater disagreement with the statement than the Monash students (-.36) and both the Monash and secondary school students have greater disagreement than the Singaporean students (Monash -.76, secondary school -1.12). As stated earlier, all the students surveyed had completed a substantial amount of mathematics at secondary level or higher (Figure $3)$.

To further elucidate the hypothesis that mathematics anxiety is a contributing factor to the low female enrolments in computing degree courses, one other question on the survey can be analysed. Students were asked to nominate the gender of their teachers in information technology and mathematics subjects. The results are shown in Figure 4. The column headed "Both" means that these students were taught by both genders at various times during their senior secondary education.

These results show that the Singaporean students have been exposed to teachers of both genders in computing to a much greater degree than the Monash students, and a slightly greater degree than the secondary school students. The gender of the mathematics teacher is more likely to be male 
in the secondary schools than in the other two groups. The higher exposure to female mathematics teachers with both the Singapore and Monash groups could indicate a positive three-way correlation between mathematics, gender of teachers and information technology.

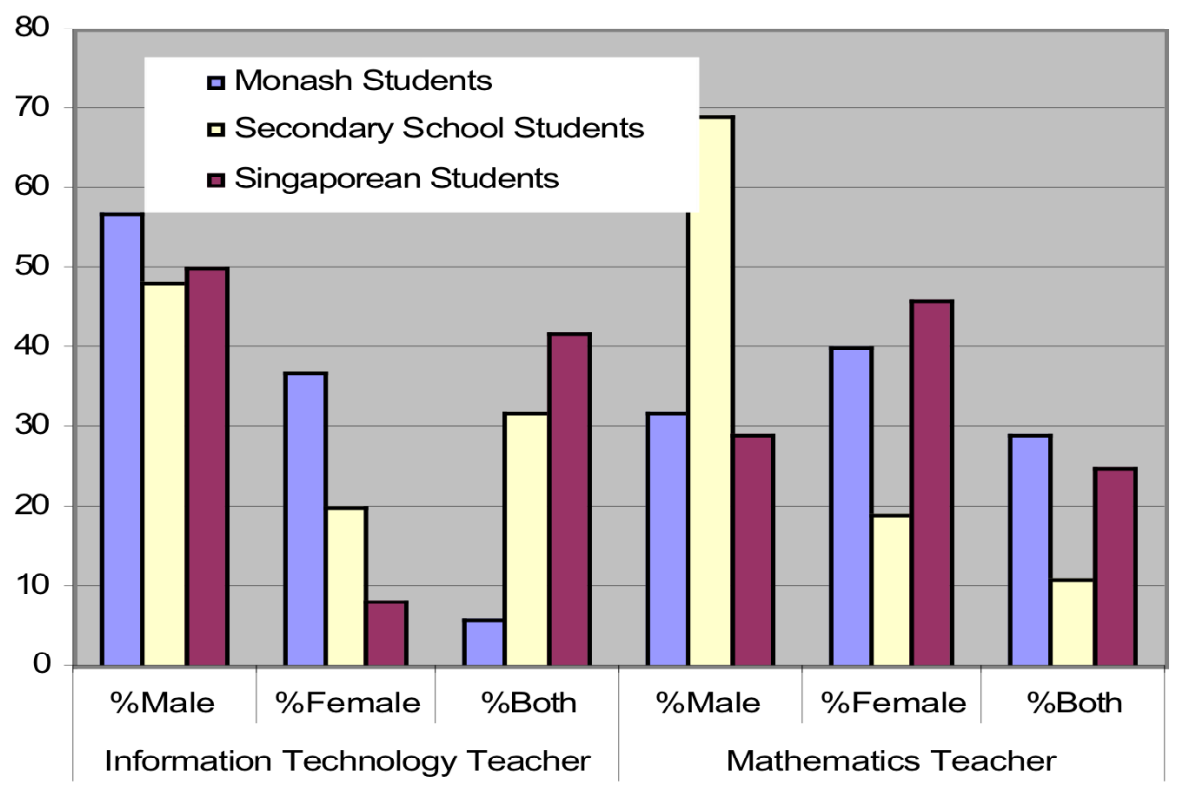

Figure 4: Gender of IT and mathematics teachers

\section{Discussion}

The statistics presented in the introduction show that as the level of mathematics requirements of a tertiary computing course is lowered, then the female enrolment increases. The survey and interview results also show that the students currently enrolled in tertiary computing courses believe that to be successful in the computing area, they need to have good mathematical ability, an opinion supported by students who are studying a computing subject at university while enrolled in noncomputing career paths, as well as the professionals in the workplace.

The survey and interview results presented support the proposition that, while computing and mathematics are closely aligned in most female minds, there is a difference in perception across culture and age regarding whether good mathematical ability is needed for success in computing. Secondary school students, the youngest cohort of the sample, are split 
almost equally between agreeing, disagreeing and being uncertain about the importance of mathematics for computing degrees (Figure 1).

The Singaporean students have been exposed to female mathematics and information technology teachers during their education to a greater degree than the Australian students, and a significantly greater percentage of them have undertaken computing degree courses. This may be ascribed to the effects of having female role models in both disciplines, and therefore having reduced mathematics anxiety, and a less gendered view of the computing career path.

There is a mathematics anxiety in females (Clarke \& Teague, 1994; Grundy, 2000), whether it can be accounted for by a lesser exposure to mathematics than their male counterparts or not. The field of computing, which is strongly founded on constructed knowledge, is believed to be more suited to the male pattern of learning than the female (Turkle, 1995). While women's subjective way of knowing needs to be valued more by society, equality of mathematical exposure and erosion of the misconception that females cannot do mathematics also need to be addressed. The data presented show that there is a lack of female role models in both mathematics and computing in Victorian secondary schools, to a greater extent than in Singapore.

\section{Conclusion}

The outcome of this study is that a dual pronged approach is needed, with both computing and mathematics professionals working together in order to dispel mathematics anxiety in females. The uncertainty of secondary school students about the connection between mathematics and computing should be capitalised on.

They need to be exposed to an equivalent amount of mathematics as their male counterparts, as well as exposed to female role models in mathematics and computing to a much greater extent than at present. Positive marketing about the benefits to females of a career path in computing would also help dispel the myth that it is a male occupation. If popular culture could also enhance this view, the gender enrolment imbalance may improve considerably, as was succinctly put in an anecdotal comment "If only Allie McBeal was a systems analyst and not a lawyer". Computing faculties have little influence on popular culture, but may benefit from looking closely at the type of mathematics prerequisite for their courses. An easing of the complexity of the mathematics prerequisite or the provision of bridging classes could result in more females enrolling in computing degrees. 
The concern of the profession over the last 20 years is reflected by the number of studies investigating why females are not embracing computing to the same extent as males (Fetler 1985, Hawkins 1985, Lim 1990, Spertus 1991, Vinagradoff 1995, Margolis \& Fisher 2002), and the formation of "Women in Computing" groups in Australia and around the world. Mathematics anxiety in females is a contributing factor to their under-representation in tertiary computing courses. Researchers in this field need to look wider than the computing discipline and combine with mathematics educators to encourage females into computing courses by working to dispel mathematics anxiety.

\section{References}

Australian Bureau of Statistics (1999). Real Time: Computers, Change and Schooling. Canberra: Commonwealth of Australia.

Beall, A. \& Sternberg, R. (1993).The Psychology of Gender. New York: Guilford Press.

Belenky, M., Clinchy, B., Goldberger, N. \& Tarule, J. (1986). Women's ways of knowing. The development of self, voice and mind. New York: Basic Books Inc.

Board of Studies (1994). Information Technology Study Design. Victoria: Board of Studies.

Budget and Statistical Services (1996). Statistics 9: Statistics for Management Information. Victoria: Monash University.

Clarke, V \& Teague, G. (1994). Encouraging girls to study computer science should we even try? Australian Educational Computing, 9(1), 17-22.

Clarke, V. \& Teague, G. (1994). A psychological perspective on gender differences in computing participation. ACM SIGCSE Bulletin, 26(1), 258-262.

DETYA (Department of Education, Training and Youth Affairs) (2001). Higher Education Student Time Series Tables 2000. Canberra: Commonwealth of Australia.

Durndell, A., Glissov, P. \& Siann, G. (1995). Gender and computing: Persisting differences. Educational Research, 37(3), 219-227.

Fetler, M. (1985). Sex differences on the California statewide assessment of computer literacy. Sex Roles, 13(3), 181-191.

Grundy, F. (2000). Mathematics in computing, a help or a hindrance for women? http: / / www.keele.ac.uk/depts / cs / staff/a.f.grundy/home/maths.htm [viewed 12 Jun 2000, verified 30 Aug 2002]

Hawkins, J. (1985). Computers and girls: Rethinking the issues. Sex Roles, 13(3), 168-180. 
Klawe, M. \& Leveson, N. (1995). Women in computing, where are we now? Communications of the ACM, 38(1), 29-35.

Koch, M. (1994). No girls allowed! Technos Quarterly for Education and Technology, 3(3), 1-8. http: / / gnn.com/gnn/ wic/ wics/ednew.html [viewed 14 Jul 1997, verified 30 Aug 2002 at http:/ / www.technos.net/tq_04/tq_03/3koch.htm]

Koertge, N. (1995). How feminism is now alienating women from science. Skeptical Inquirer, 19(2), 42-43.

Lim, G.K. (1990). WIT: The Singaporean way. The Computer Bulletin, 2(1), 18-21.

Mather, J. (1996). Why are there few women scientists? Systemic Discrimination, April, 6-9.

Margolis, J. \& Fisher, A. (2002). Unlocking the Clubhouse: Women in Computing. The MIT Press Cambridge, Massachusetts.

Pearl, A. (1995). Women in computing. Communications of the ACM, 38(1), 26-28.

Roberts, P. (1995). Why can't a computer think more like a woman? In P. Bishop, M. Dyer \& P. Griffin (Eds), Women, Computing and Culture: Proceedings of the1994 Conference. ( pp.23-35). Adelaide: Research Centre for Gender Studies, University of South Australia.

Siann, G. \& Callaghan, M. (2001). Choices and barriers: Factors influencing women's choice of higher education in science, engineering and technology. Journal of Further and Higher Education, 25(1), 85-95.

Spender, D. (1995). From page to screen: Women and the new information medium. Digital Media, 4(8), 35-38.

Spertus, E. (1991). Why are there so few female computer scientists? MIT Artificial Intelligence Laboratory Technical Report No. 1315 M.I.T. [verified 30 Aug 2002] http://www.mills.edu/ACAD_INFO/MCS/SPERTUS/Gender/pap/pap.html

Turkle, S. (1995). Life on the Screen. New York: Simon \& Schuster.

Vinogradoff, V. (1995). Technology and girls. In P. Bishop, M. Dyer \& P. Griffin (Eds), Women, Computing and Culture: Proceedings of the1994 Conference. ( pp.8495). Adelaide: Research Centre for Gender Studies, University of South Australia.

Catherine Lang, School of Information Technology

Swinburne University of Technology

clang@it.swin.edu.au

http:/ / www.it.swin.edu.au/staff/clang 